\title{
Radio-Histopathological Aspects of Breast Nodules in a Sub-Saharan African City (Ouagadougou, Burkina Faso)
}

\author{
Nina-Astrid Nde Ouedraogo ${ }^{{ }^{*}}$, Bénilde Ma Kambou Tiemtore ${ }^{1}$, Yobi Alexis Sawadogo², \\ Boubakar Ouattara ${ }^{3}$, Prosper David Lamien ${ }^{3}$, Madina Napon ${ }^{4}$, Ousséini Diallo ${ }^{3}$, Abel Bamouni ${ }^{3}$, \\ Claudine Lougue Sorgho4, Rabiou Cisse ${ }^{3}$
}

\footnotetext{
${ }^{1}$ Radiology Department of Charles de Gaulle Teaching Paediatric Hospital, Ouagadougou, Burkina Faso

${ }^{2}$ Gynaeco-Obstetric Department of Bogodogo Teaching Hospital, Ouagadougou, Burkina Faso

${ }^{3}$ Radiology Department of Yalgado Ouedraogo Teaching Hospital, Ouagadougou, Burkina Faso

${ }^{4}$ Radiology Department of Charles de Gaulle Teaching Paediatric Hospital, Ouagadougou, Burkina Faso

Email: *ninawed@hotmail.com
}

How to cite this paper: Ouedraogo, N.-A.N., Tiemtore, B.M.K., Sawadogo, Y.A., Ouattara, B., Lamien, P.D., Napon, M., Diallo, O., Bamouni, A., Sorgho, C.L. and Cisse, R. (2018) Radio-Histopathological Aspects of Breast Nodules in a Sub-Saharan African City (Ouagadougou, Burkina Faso). Open Journal of Medical Imaging, 8, 89-96. https://doi.org/10.4236/ojmi.2018.83011

Received: August 31, 2018

Accepted: September 23, 2018

Published: September 26, 2018

Copyright $\odot 2018$ by authors and Scientific Research Publishing Inc. This work is licensed under the Creative Commons Attribution International License (CC BY 4.0).

http://creativecommons.org/licenses/by/4.0/ (c) (i) Open Access

\begin{abstract}
Objective: To determine the diagnostic contribution of breast microbiopsy percutaneously under ultrasound guidance. Methodology: Retrospective descriptive study conducted from January 2014 to October 2017. The included patients had an ultrasound-guided breast microbiopsy after a mammographic and ultrasound scan. The variables collected were gender, age, nodule size, ACR classification and anatomopathologic diagnosis. Results: 347 nodules were explored in 313 patients. There were 300 women (95.85\%) and 13 men (4.15\%), a gender ratio of 23.07 . The average age was $44.64 \pm 14.18$ years. The average size of the nodules was $30.33 \pm 19.58 \mathrm{~mm}$. There were $53.89 \%$ ACR4 grade nodules, $48 \%$ ACR5 nodules and $32.28 \%$ ACR3 nodules. $86.49 \%$ of ACR3 nodules were benign and $97.92 \%$ of ACR5 nodules were actually malignant. Malignant tumors accounted for $50.29 \%$ of the nodules and were dominated by invasive breast carcinomas in $98.26 \%$. The average age of patients with malignant tumors was $49.15 \pm 11.55$ years. $16 \%$ of patients with malignancy were aged under 40 years old. Conclusion: The diagnostic yield was satisfactory and there was a good correlation between the rate of malignant and benign lesions and the positive predictive values of malignancy in the literature.
\end{abstract}

\section{Keywords}

Breast Microbiopsy, Ultrasound Guidance, Mammary Nodule, Breast Cancer 


\section{Introduction}

Breast cancer is growing in sub-Saharan Africa. In Burkina Faso, it accounted for $23.81 \%$ of all cancers and $49.36 \%$ of female cancers in 1998 [1] [2]. These figures are increasing, with an incidence of 1144 new cases per year according to the World Health Organization in 2014.

This affection poses many difficulties in our country for its care. Thus, in routine practice, lumpectomy or mastectomy can be performed without prior histological diagnosis. However, recommendations stipulate that more than $70 \%$ of cancers must be diagnosed prior to surgery in order to adapt the therapeutic procedure [3].

Breast biopsies can prevent surgical biopsies. The indications for these samples are based on the ACR BI-RADS classification and essentially interest to ACR5, ACR4 lesions, and in some cases, ACR3 lesions.

Several studies have analyzed the positive predictive value (PPV) of categories 3, 4 and 5 of BIRADS [4]. In a literature review conducted by Kastelman et al. [5], this PPV was 0 to $8 \%$ for category 3, 4 to $69 \%$ for category 4 and 5 to $100 \%$ for category 5. In Burkina Faso, existing studies have mainly focused on fine needle aspiration biopsy [6].

There is not, to our knowledge, studies to date on the histopathological and radiological correlations mammary tumors performed in our context. However, since the advent of breast microbiopsy, the fine needle aspiration biopsies have decreased in breast pathology.

The aim of this work was to show the diagnostic contribution of percutaneous breast microbiopsy under ultrasound guidance in our context.

\section{Methodology}

This was a descriptive and retrospective study, conducted from January 2014 to October 2017. The included patients had nodules classified ACR3, 4 or 5 after a mammographic and ultrasound scan, with a histology result available. The breast microbiopsies were performed under ultrasound guidance. The biopsy punctures were performed by an experienced radiologist. The procedure of the microbiopsy and the risks were explained to the patient before each action. Consent was obtained orally.

We used automatic biopsy needles of 14 gauge $(G)$ and $10 \mathrm{~cm}$ in length. Ultrasound location and strict asepsis of the cutaneous levels with povidone-iodine were performed. Local anesthesia was performed at the skin entry point and along the needle path to the edge of the nodule with $10 \mathrm{ml}$ of $2 \%$ lidocaine. The needle was introduced to the edge of the target under ultrasound guidance using a linear probe of 12 to $16 \mathrm{Mz}$. Three to four samples were then taken per nodule (Figure 1).

Samples were placed in formalin flasks and sent to the pathology laboratory for analysis. Microbiopsies were all performed on an outpatient basis.

The variables collected were gender, age, nodule size, ACR classification and pathology diagnosis. 


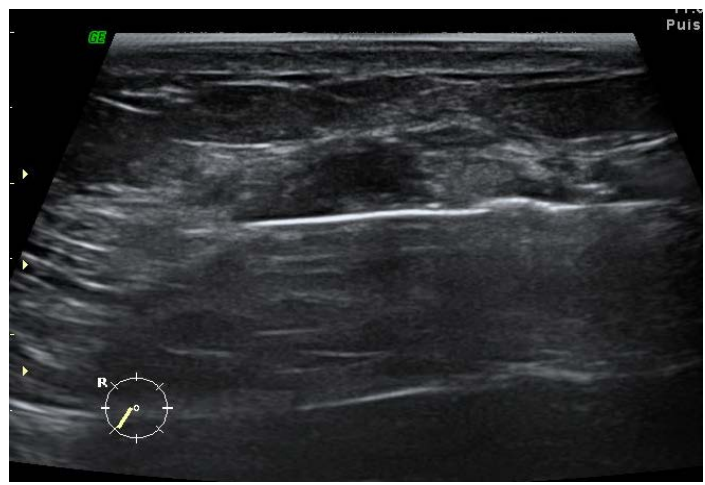

(a)

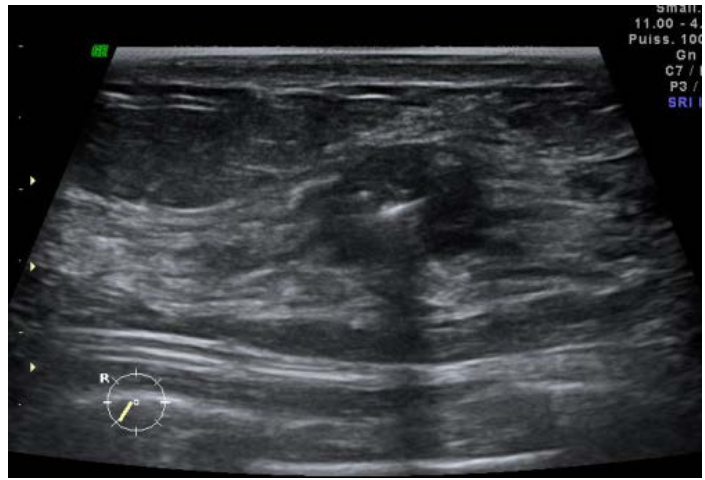

(b)

Figure 1. Ultrasound sections with biopsy needle within the nodule ((a) longitudinal view; (b) transverse view).

Data analysis was performed using the Epi Info 7.3 software.

\section{Results}

Our sample consisted of 347 nodules from 313 subjects. There were 300 women (95.85\%) and 13 men (4.15\%). The average age was $44.64 \pm 14.18$ years. The average size of the nodules was $30.33 \pm 19.58 \mathrm{~mm}$. The average age of patients with malignant tumors was $49.15 \pm 11.55$ years. $16 \%$ of patients with malignancy were aged under 40 years old.

The distribution of our sample according to the ACR BIRADS classification noted 112 ACR3 nodules (Figure 2) or 32.28\%, 187 ACR4 nodules (Figure 3) or $53.89 \%$ and 48 ACR5 nodules (Figure 4 ) or $13.83 \%$.

Biopsies were contributive in 344 cases (99.13\%). The nodules sat on the left in $54.65 \%$ of cases and on the right in $45.35 \%$.

The histopathological findings showed $50.29 \%$ malignant nodules, $46.22 \%$ benign nodules and $3.49 \%$ borderlines nodules. Malignant tumors were dominated by invasive breast carcinomas in $98.26 \%$. Benign tumors were mainly represented by dystrophic and inflammatory lesions in $32.08 \%$ and $27.04 \%$. Borderlines lesions consisted mainly of atypical ductal hyperplasias. Invasive ductal carcinomas were the most common lesions among malignant lesions. The histological types of nodules are reported in Table 1. 


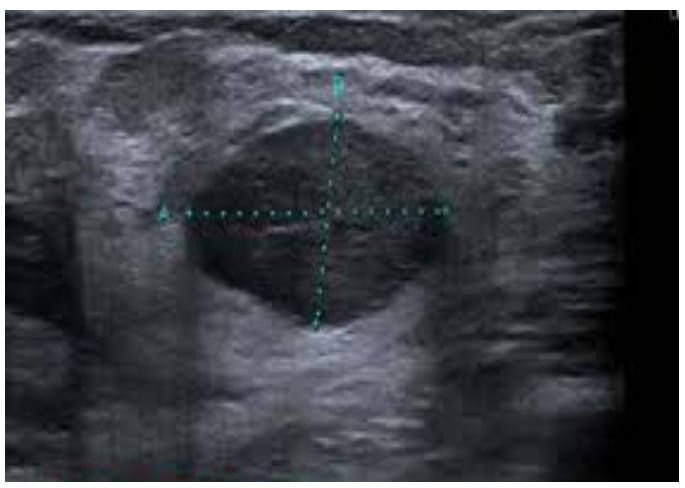

Figure 2. Ultrasound appearance of an ACR3 grade nodule. The contours are circumscribed. The major axis is parallel to the cutaneous levels.

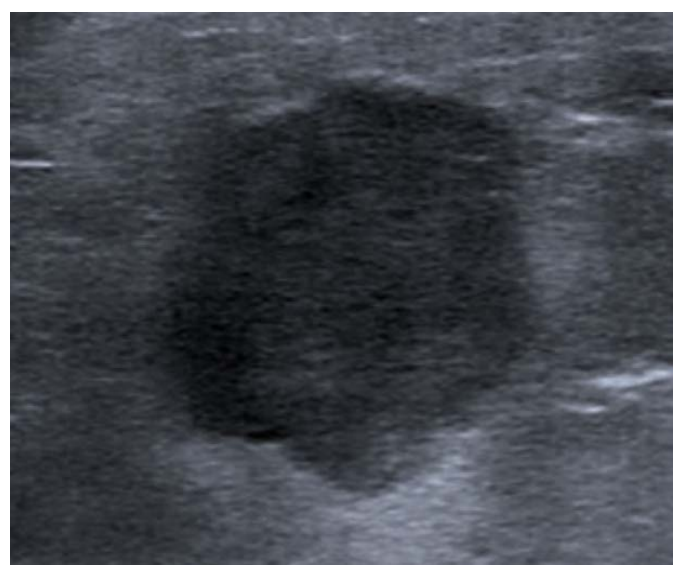

Figure 3. Ultrasound appearance of an ACR4 grade nodule. Contours are partially hidden (arrow).

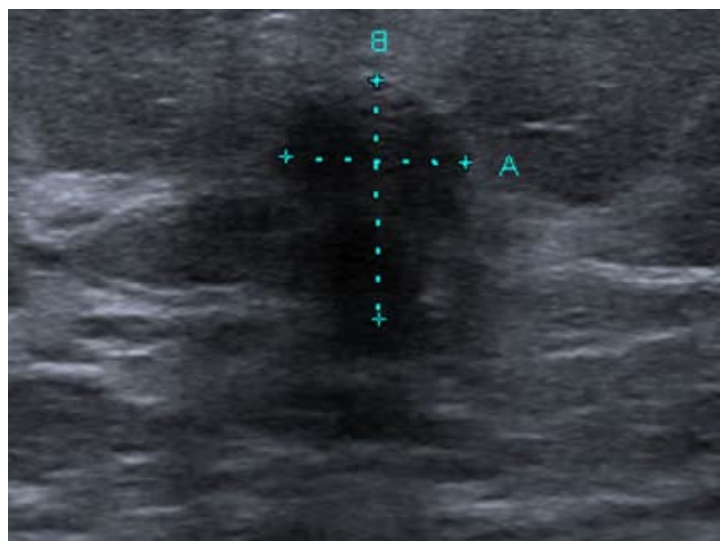

Figure 4. Ultrasound appearance of an ACR5 grade nodule. The contours are irregular, the major axis of the nodule is perpendicular to the cutaneous levels and there is a posterior attenuation of the echoes.

There were 97.92\% $(n=47)$ of malignant lesions in ACR5, 64.32\% ( $n=119)$ in ACR4 and 6.31\% $(n=7)$ in ACR3. The histological aspects of the nodules according to the ACR classification are noted in Table 2. 
Table 1. Histopathological aspect of breast nodules explored through microbiopsy.

\begin{tabular}{ccc}
\hline Histological type & Frequency & Percentage \\
\hline Malignant tumor & 23 & \\
Grade 1 CCI & 125 & 13.29 \\
Grade 2 CCI & 21 & 72.25 \\
Grade 3 CCI & 1 & 12.14 \\
Mucineous carcinoma & 2 & 0.58 \\
Liposarcoma & 1 & 1.16 \\
Metastasis & 173 & 0.58 \\
& & 100 \\
Benign tumor & & \\
Dystrophic lesions & 51 & 32.08 \\
Inflammatory lesions & 43 & 27.04 \\
Fibroadenomas & 35 & 22.01 \\
Adenosis & 17 & 10.69 \\
Lactating adenoma & 4 & 2.52 \\
Intraductal papilloma & 4 & 2.52 \\
Phyllodes tumor & 3 & 1.89 \\
Hemangioma & 2 & 1.26 \\
& 159 & 100 \\
Border tumor & & \\
HCA & 12 & 100 \\
\hline
\end{tabular}

Table 2. Histological findings according to the ACR classification.

\begin{tabular}{ccccccc}
\hline & \multicolumn{2}{c}{ Malignant nodules } & \multicolumn{2}{c}{ Benign nodules } & \multicolumn{2}{c}{ Border nodules } \\
\hline & Frequency & $\%$ & Frequency & $\%$ & Frequency & $\%$ \\
\hline ACR3 & 7 & 6.31 & 96 & 86.48 & 8 & 7.21 \\
ACR4 & 119 & 64.32 & 62 & 33.51 & 4 & 2.17 \\
ACR5 & 47 & 97.92 & 1 & 2.08 & 0 & \\
\hline
\end{tabular}

\section{Discussion}

Our study highlighted the fact that the microbiopsy of breast nodules had an excellent yield and that malignant nodules predominated in our sample.

The average age of the patients in our series (44.64 years) was younger than that found by Moifo et al. [7] in Cameroon (49 years), but higher than that of Tsonga et al. [8] in Gabon, who had found an average age of 41 years.

The average size of analyzed nodules was higher than that found by Tsonga et al. [8] which was $15 \mathrm{~mm}$. This difference may be related to the modalities of discovery of the nodules. Indeed, in their sample, the authors were interested in the nodules discovered during a systematic screening, therefore of smaller size, contrary to our study where the patients were referred after clinical discovery of nodules.

The BIRADS classification of the ACR permits to classify the nodules explored through imaging according to the predictive value of their malignancy potential, notably on the ultrasound contour criterion, and also makes it possible to pro- 
pose a course of action.

ACR5 nodules typically have a positive predictive value of malignancy (PPV) greater than $70 \%$ [9]. In our sample, this PPV was excellent, as $97.92 \%$ of ACR5 nodules were actually malignant in histology. Among these nodules, we found a predominance of invasive breast carcinomas in agreement with several studies [8] [10].

The PPV of malignancy in our sample for ACR4 lesions (64.32\%) was in accordance with that found in the literature. This class includes a wide range of benign, borderline or malignant lesions. It is therefore necessary for this group to carry out a diagnostic microbiopsy.

ACR3 nodules are nodules with a PPV of malignancy $<3 \%$. These nodules do not immediately require microbiopsy but short-term monitoring. There was a good PPV of benignity in this class with $86.49 \%$ of actually benign nodules. The proportion of benign nodules in this class corroborated those in the literature [11]. These nodules were mainly represented by dystrophic and inflammatory lesions.

However, we noted a high rate of malignant nodules in the ACR3 class, higher than international recommendations. Other authors in sub-Saharan Africa had also noted rates of malignant lesions higher than international recommendations: Kamga et al. [12], Moifo et al. [7] and Mayi Tsonga et al. [8] who had respectively demonstrated rates of malignancy of $13.3 \%, 3.5 \%$ and $11 \%$.

It is important to note that some malignant lesions may look falsely reassuring on ultrasound, in connection with a rapid growth of tumor cells, giving the tumor a rounded or oval appearance, of benign appearance. Thus, Lamb PM [13] found in his study $10 \%-20 \%$ of malignant lesions with regular contours. It is important to monitor ACR 3 nodules on ultrasound in the short term; they are not biopsied, so as not to ignore a malignant lesion of benign presentation. As soon as there is an increase in size or a morphological change of the nodule, a histological examination would be necessary [9].

Among the benign tumors, there was a predominance of dystrophic and inflammatory lesions, followed by fibroadenomas. However, most studies show a predominance of fibroadenomas in benign breast tumors [8] [10]. It is a tumor of the young, hormone-dependent woman whose appearance may vary with time [14].

The borderlignes lesions consisted exclusively of atypical ductal hyperplasia. It should be noted that these nodules were classified ACR3 or ACR4 on ultrasound. These are lesions similar to carcinomas in situ, with a relative risk of cancer multiplied by 4 to 5 [15].

Our study presents limitations related to sampling that has been done out only in urban areas, which can generate biases due to the different way of life, education and medical equipment of the health facilities in the country.

\section{Conclusions}

Our study showed that ultrasound-guided breast microbiopsy performed well in 
our context. It allowed to describe the histological types of mammary nodules explored by ultrasound-guided microbiopsy and showed that the malignancy rates of the ACR4 and ACR5 classes were in accordance with the data in the literature. However, the rate of malignant lesions in the ACR3 class was higher than international recommendations.

Multicentric studies including the rural areas, would permit to investigate possible features of breast nodules in sub-Saharan Africa and also optimize the characterization performance of these nodules.

\section{Conflicts of Interest}

The authors declare no conflicts of interest regarding the publication of this paper.

\section{References}

[1] Goumbri, O.M., Domagni, O.E., Sanou, A.M., Konsegre, V., Soudre, R.B., et al. (2009) Aspects épidémiologiques et histopathologiques des cancers au Burkina Faso. Journal africain du cancer/ African Journal of Cancer, 1, 207-211. https://doi.org/10.1007/s12558-009-0052-X

[2] Sano, D.I., Cisse, R., Dao, B., Lankoande, J., Traore, S.S.L., Soudre, R.B., et al. (1998) Le cancer du sein: Problèmes diagnostiques et thérapêutiques au CHU de Ouagadougou. Médecine d Afrique Noire, 45, 297-301.

[3] O’Higgins, N., Linos, D.A., Blichert-Toft, M., Cataliotti, L., de Wolf, C., Rochard, F., et al. (1997) European Guidelines for Quality Assurance in the Surgical Management of Mammographically Detected Lesions. European Breast Cancer Working Group. Annales Chirurgiae et Gynaecologiae, 87, 110-112. http://europepmc.org/abstract/med/9598249

[4] D’orsi, C.J., Bassett, L.W., Berg, W.A., Feig, S.A., Jackson, V.P. and Kopans, D.B. (2003) Breast Imaging Reporting and Data System: ACR BI-RADS-Mammography. Journal of the American College of Radiology, 4.

[5] Kestelman, F.P., de Souza, G.A., Thuler, L.C., Martins, G., de Freitas, V.A.R. and de Oliveira Canella, E. (2007) Breast Imaging Reporting and Data System-BI-RADS ${ }^{\oplus}$ : Positive Predictive Value of Categories 3, 4 and 5. A Systematic Literature Review. Radiologia Brasileira, 40, 173-177. https://doi.org/10.1590/S0100-39842007000300008

[6] Cisse, R., Lougue, C., Sano, D., Bamouni, A.Y., Tapsoba, T.L., Sakande, B., et al. (2002) Pathologie tumorale mammaire avant l'âge de 30 ans chez la femme Africaine à Ouagadougou, Burkina Faso. Imagerie de la Femme, 12, 245-251.

[7] Moifo, B., Guegang, G.E., Foumane, P., Sando, Z., Zeh, O.F., WankoWoguep, V.L., et al. (2014) Valeur des signes échographiques dans la prédiction du potentiel malin des masses mammaires. Journal Africain d Imagerie Médicale, 5. http://jaim-online.net/index.php/jaim/article/view/12

[8] Mayi-Tsonga, S., Meye, J.-F., Ngou-Mve-Ngou, J.-P., Mendome, G. and Mounanga, M. (2006) Corrélation radio-histologique des lésions mammaires infracliniques à partir de la classification BI-RADS (étude gabonaise). Cahiers détudes et de recherches francophones/ Santé, 16, 179-183.

[9] Mendelson, E.B., Baum, J.K., Berg, W.A., Merritt, C.R.B. and Rubin, E. (2003) Breast Imaging Reporting and Data System, BI-RADS: Ultrasound. Journal of the 
American College of Radiology.

[10] Mobima, T., Ouiamon, R., Koandongui, F., Koffi, B., et al. (2016) Corrélations histo-échographiques des lésions mammaires à Bangui (RCA). Journal Africain d Imagerie Médicale, 7. http://jaim-online.net/index.php/jaim/article/view/256

[11] Leblay, F., Anglade, E., Mayras, C. and Dauver, N. (2004) Opacités mammographiques: Utilisation de la classification BI-RADS ${ }^{\mathrm{TM}}$ de l'ACR et corrélation avec la biopsie stéréotaxique (14-G) sur table dédiée: A propos de 135 cas: Mammographic opacities: Use of the ACR BI-RADS ${ }^{\mathrm{TM}}$ lexicon. Imagerie de la Femme, 14, 229-235. https://doi.org/10.1016/S1776-9817(04)94816-X

[12] Kamga, J.E.G., Moifo, B., Sando, Z., Goudjou, E.G., Amvene, S.N. and Fotsin, J.G. (2013) Fiabilité des utilisateurs de la classification BI-RADS en milieu tropical pour la prédiction de la malignité des lésions mammaires. Médecine et Santé Tropicales, 23, 439-444.

[13] Lamb, P.M., Perry, N.M., Vinnicombe, S.J. and Wells, C.A. (2000) Correlation between Ultrasound Characteristics, Mammographic Findings and Histological Grade in Patients with Invasive Ductal Carcinoma of the Breast. Clinical Radiology, 55, 40-44. https://doi.org/10.1053/crad.1999.0333

[14] Jalaguier-Coudray, A. and Thomassin-Piana, J. (2014) Les Masses Solides: Quelles Lésions Anatomopathologiques Sous-Jacentes? Journal de Radiologie Diagnostique et Interventionnelle, 95, 158-174. https://doi.org/10.1016/j.jradio.2013.12.002

[15] Fitzgibbons, P.L., Henson, D.E. and Hutter, R.V. (1998) Benign Breast Changes and the Risk for Subsequent Breast Cancer: An Update of the 1985 Consensus Statement. Archives of Pathology \& Laboratory Medicine, 122, 1053-1055. 